\title{
UTILIZAÇÃO DA TDR PARA MONITORAMENTO DA SOLUÇÃO DE NITRATO DE POTÁSSIO EM LATOSSOLO VERMELHO-AMARELO
}

\author{
LEONARDO DO N. LOPES ${ }^{1}$, CLAUDINEI F. SOUZA ${ }^{2}$, BRUNO DE L. SANTORO 3
}

RESUMO: O conhecimento da distribuição e armazenamento da solução no solo é de grande importância para a agricultura, pois a interação entre os nutrientes e a água é um dos fatores que influenciam diretamente no rendimento das culturas. Das várias técnicas utilizadas para o monitoramento da solução no solo, a reflectometria no domínio do tempo (TDR) vem sendo bastante difundida entre os pesquisadores por apresentar inúmeras vantagens, dentre as quais a mensuração em tempo real e a possibilidade de leituras automatizadas. O principal objetivo desta pesquisa foi avaliar a distribuição da solução de $\mathrm{KNO}_{3}$ no perfil de um Latossolo Vermelho-Amarelo. Sondas de Reflectometria no Domínio do Tempo (TDR) foram utilizadas para monitorar a distribuição de solução no solo aplicada por gotejadores de fluxo constante nas vazões de 2; 4 e $8 \mathrm{~L} \mathrm{~h}^{-1}$. Considerando-se os resultados de diferentes perfis, observou-se maior armazenamento da solução próxima ao gotejador, diminuindo progressivamente para frente de molhamento. Pouco mais da metade da solução aplicada $(65 \%)$ foi armazenada na primeira camada $(0-0,10 \mathrm{~m})$ para todos os ensaios, e $22 \%$ foi armazenada na próxima camada $(0,10-0,20 \mathrm{~m})$. Comparando-se diferentes taxas de aplicação, observou-se maior armazenamento de água para o gotejador de $4 \mathrm{~L} \mathrm{~h}^{-1}$, com 60; 72 e $63 \%$ de solução de $\mathrm{KNO}_{3}$ aplicada acumulada na primeira camada $(0-0,10 \mathrm{~m})$ para gotejadores de $2 ; 4$ e $8 \mathrm{~L} \mathrm{~h}^{-1}$, respectivamente. Os resultados sugerem que, com base no volume e frequência utilizada neste experimento, seria vantajoso aplicar pequenas quantidades de água em intervalos mais frequentes para reduzir perdas por percolação.

PALAVRAS-CHAVE: reflectometria no domínio do tempo, umidade do solo, condutividade elétrica do solo, volume de solo molhado.

\section{USE OF TDR FOR MONITORING THE POTASSIUM NITRATE SOLUTION IN DYSTROPHIC RED-YELLOW LATOSSOL}

\begin{abstract}
Knowledge of water distribution in soil is of great importance to agriculture, since water is one of the factors that most influence the yield of crops. There are many techniques used for monitoring of soil water content, the Time Domain Reflectometry (TDR) has been widespread among researchers to present several advantages, among which the determination in real time and possibility of automated readings. The main goal of this research was to evaluate the $\mathrm{KNO}_{3}$ solution distribution in a profile of a Dystrophic Red-Yellow latossol. Time domain reflectometry (TDR) probes were used to monitor the soil solution distribution from drippers discharging at constant flow rates of 2, 4 and $8 \mathrm{~L} \mathrm{~h}^{-1}$ in soil. Considering the results from different profiles, we observed greater solute storage near the dripper decreasing gradually towards the wetting front. About half of the applied $\mathrm{KNO}_{3}$ solution $(65 \%)$ was stored in the first layer $(0-0.10 \mathrm{~m})$ for all experiments and 22 $\%$ was stored in the next layer (0.10-0.20 m). Comparing different dripper flow rates, we observed higher solution storage for $4 \mathrm{~L} \mathrm{~h}^{-1}$, with 60,72 and $63 \%$ of the applied $\mathrm{KNO}_{3}$ solution accumulated in the first layer $(0-0.10 \mathrm{~m})$ for dripper flow rates of 2,4 and $8 \mathrm{~L} \mathrm{~h}^{-1}$, respectively. The results suggest that based on the volume and frequency used in this experiment, it would be advantageous to apply small amounts of solution at more frequent intervals to reduce deep percolation losses of applied water and solutes.
\end{abstract}

KEYWORDS: time domain reflectometry, soil moisture, soil electrical conductivity, wetted soil volume.

\footnotetext{
${ }^{1}$ Eng ${ }^{\circ}$ Ambiental, Secretaria de Estado do Meio Ambiente, Coordenadoria de Recursos Hídricos - CRHi, Taubaté - SP, Fone: (0XX12) 3632-0100, leolopess2005@yahoo.com.br.

${ }^{2}$ Eng ${ }^{\mathrm{o}}$ Agrônomo, Professor Adjunto, Centro de Ciências Agrárias, Universidade Federal São Carlos, Araras - SP, Fone: (0XX19) 3543.2616, cfsouza@cca.ufscar.br.

${ }^{3}$ Eng $^{\mathrm{o}}$ Ambiental, Mestrando em Agricultura e Ambiente, CCA/UFSCar, blsantoro@ hotmail.com.

Recebido pelo Conselho Editorial em: 28-7-2009
}

Aprovado pelo Conselho Editorial em: 14-8-2010 


\section{INTRODUÇÃO}

No Brasil, a aplicação de fertilizantes por meio da fertirrigação vem firmando-se nos últimos anos como uma técnica muito promissora, principalmente entre os usuários de sistemas de irrigação localizada e pivô central. De acordo com COELHO (1994), o nitrogênio é o elemento mais frequentemente aplicado via água de irrigação, apresentando em relação aos outros nutrientes, alta mobilidade no solo e, consequentemente, alto potencial de perdas, principalmente por lixiviação. Com o uso da fertirrigação, pode-se parcelar a aplicação dos fertilizantes nitrogenados de acordo com a demanda da cultura, reduzindo as perdas sem onerar o custo de produção. A eficácia do gotejamento, entretanto, depende do manejo racional de todo o sistema, inclusive da fertirrigação (MAROUELLI \& SILVA, 2000).

Apesar do uso difundido da fertirrigação via irrigação por gotejamento, informações sobre o movimento simultâneo da água e dos sólidos dissolvidos são escassas (CLOTHIER \& SAUER, 1988). Sabe-se que, na irrigação por gotejamento, a distribuição da água concentra-se ao redor do gotejador, resultando em acúmulo de sais na extremidade do bulbo molhado do solo (HAMZA \& ALYMORE, 1992; GREEN\& CLOTHIER, 1995; SOUZA et al., 2009).

O fornecimento de nutrientes para as plantas pela fertirrigação está em função da concentração dos nutrientes na água de irrigação, concentração da solução do solo, evapotranspiração e nutrientes absorvidos pelas plantas. Informações detalhadas sobre a absorção de nutrientes pelas plantas são fundamentais para a otimização da fertirrigação (HAGIN \& LOWENGART, 1996).

O monitoramento da fertirrigação deve ser feito para avaliar o manejo em si, com base nos impactos causados no solo que possam influenciar no desenvolvimento da plantas, que deve envolver o acompanhamento da aplicação dos fertilizantes observando a concentração da solução injetada, concentração da solução final na saída dos emissores, uniformidade de distribuição ao longo da área e distribuição dos nutrientes no perfil do solo (SOUSA \& COELHO, 2001).

Segundo SPALDING et al. (1982), a aplicação de quantidades excessivas de fertilizantes nitrogenados tem sido frequentemente sugerida como a principal fonte de contaminação de águas subterrâneas. Para prevenir e minimizar a poluição de água subterrânea com nitrato, é necessário o controle das taxas de nitrogênio aplicadas anualmente no solo, além dos fatores intervenientes na mobilidade do ânion no solo.

EXNER et al. (1991) verificaram movimento profundo de nitrato, em diferentes taxas de aplicação, sob condições de irrigação, cujos resultados indicam que 95\% do nitrato aplicado foram lixiviados para baixo da zona radicular da cultura.

Conforme SOUZA et al. (2007), os métodos mais indicados e precisos para o monitoramento do nitrato no solo são a utilização de nitrogênio $(\mathrm{N})$ marcado e avaliação em lisímetros de drenagem, entretanto a técnica da TDR (Reflectometria no Domínio do Tempo) apresenta potencial para este monitoramento.

Para medidas precisas de umidade do solo e condutividade elétrica em laboratório e campo, existe uma tendência de utilização da técnica TDR, onde se recomenda o levantamento de uma curva de calibração para cada tipo de solo, um inconveniente normalmente aceitável, comparado com as vantagens que apresenta em relação às outras técnicas.

As vantagens inerentes da técnica TDR, como a precisão, método não destrutivo, a não utilização de radiação ionizante, possibilidade de automação e acoplamento a dispositivos multiplicadores de leituras, pouca influência da textura, densidade e salinidade, são justificativas fortes para a adoção cada vez maior da técnica em substituição a outros métodos (COELHO \& OR 1996; SOUZA et al., 2006a).

A TDR tem sido usada para a avaliação do movimento de solutos no solo (NADLER et al., 1999; MMOLAWA \& OR, 2000; SOUZA et al., 2007; SOUZA \& FOLEGATTI, 2010). Tal 
aplicação pode trazer benefícios para a pesquisa em fertirrigação, de forma a dar subsídios ao entendimento da dinâmica de solutos sob diferentes manejos de fertirrigação. Sendo assim, objetivou-se, neste trabalho, estudar a formação do bulbo molhado, avaliando-se os efeitos da relação água-solo-soluto que possam afetar a distribuição da solução no solo, a fim de promover uma irrigação racional, considerando as questões de sustentabilidade ambiental.

\section{MATERIAL E MÉTODOS}

O experimento foi conduzido em um ambiente protegido (casa de vegetação) de $140 \mathrm{~m}^{2}$, numa área experimental do Departamento de Ciências Agrárias da Universidade de Taubaté, localizada no município de Taubaté - SP (latitude 2301'55,25"; longitude 4330'39,74" e altitude de $571 \mathrm{~m})$.

O tipo de solo da área é classificado como Latossolo Vermelho-Amarelo, segundo a classificação brasileira de solos (EMBRAPA, 1999). As características físico-hídricas e químicas do solo estão descritas na Tabela 1.

TABELA 1. Características físico-hídricas e químicas do solo na camada de 0 a 0,6 m. Physical and chemical characteristics of the soil in the 0 to $0.6 \mathrm{~m}$ layer.

\begin{tabular}{|c|c|c|c|c|c|c|c|c|c|c|}
\hline \multicolumn{11}{|l|}{ Físico-hídricas } \\
\hline \multirow{2}{*}{\multicolumn{2}{|c|}{$\begin{array}{l}\text { Profundidade } \\
\mathrm{m}\end{array}$}} & $\mathrm{CC}$ & PMP & $\mathrm{p}$ & Ds & $\mathrm{Dp}$ & \multirow{2}{*}{$\begin{array}{c}\text { VIB } \\
\mathrm{mm} \mathrm{h}^{-1}\end{array}$} & Areia & Silte & Argila \\
\hline & & \multicolumn{3}{|c|}{$\mathrm{m}^{3} \mathrm{~m}^{-3}$} & \multicolumn{2}{|c|}{$\mathrm{g} \mathrm{cm}^{-3}$} & & \multicolumn{3}{|c|}{$\%$} \\
\hline $0-0,20$ & & 0,34 & 0,21 & 0,51 & 1,30 & 2,70 & 13,20 & 59 & 13 & 28 \\
\hline $0,20-0,40$ & & 0,33 & 0,21 & 0,50 & 1,35 & 2,70 & 9,40 & 57 & 13 & 30 \\
\hline $0,40-0,60$ & & 0,32 & 0,20 & 0,49 & 1,39 & 2,70 & 9,50 & 58 & 13 & 29 \\
\hline \multicolumn{11}{|l|}{ Químicas } \\
\hline Profundidade & $\mathrm{pH}$ & $\mathrm{P}$ & $\mathrm{MO}$ & $\mathrm{H}+\mathrm{Al}$ & K & $\mathrm{Ca}$ & $\mathrm{Mg}$ & SB & CTC & V \\
\hline $\mathrm{m}$ & $\mathrm{CaCl}_{2}$ & $\mathrm{mg} \mathrm{dm}^{-3}$ & $\%$ & \multicolumn{6}{|c|}{$\mathrm{mmol} \mathrm{dm}^{-3}$} & $\%$ \\
\hline $0-0,20$ & 5,00 & 12 & 7 & 23 & 1,40 & 23 & 12 & 36,40 & 59,40 & 61 \\
\hline $0,20-0,40$ & 4,30 & 2 & 6 & 34 & 0,70 & 7 & 4 & 11,70 & 45,70 & 26 \\
\hline $0,40-0,60$ & 4,50 & 3 & 5 & 22 & 1,30 & 10 & 7 & 18,30 & 40,30 & 45 \\
\hline \multicolumn{11}{|c|}{$\begin{array}{l}\mathrm{CC} \text { - capacidade de campo; PMP - ponto de murcha permanente; } \mathrm{p} \text { - porosidade; Ds - densidade de solo; } \mathrm{Dp} \text { - densidade de } \\
\text { partícula; VIB - velocidade de infiltração básica; } \mathrm{pH} \text { - potencial de hidrogênio; } \mathrm{P} \text { - fósforo; MO - matéria orgânica; H+ Al - } \\
\text { acidez potencial; } \mathrm{K} \text { - potássio; } \mathrm{Ca} \text { - cálcio; } \mathrm{Mg} \text { - magnésio; } \mathrm{SB} \text { - soma de bases; } \mathrm{CTC} \text { - capacidade de troca catiônica; } \mathrm{V} \text { saturação } \\
\text { de bases }\end{array}$} \\
\hline
\end{tabular}

As sondas utilizadas no experimento foram construídas no Laboratório de Mecânica dos Solos da Universidade de Taubaté - UNITAU, de acordo com o procedimento descrito por SOUZA et al. (2006a).

Para a instalação das sondas de monitoramento, abriu-se uma trincheira com dimensões de $1,20 \mathrm{~m}$ x 0,80 m (largura e profundidade), conforme Figura 1, seguindo-se a metodologia proposta por SOUZA et al. (2007).

Foram instaladas 150 sondas de TDR em três paredes da trincheira, sendo 50 sondas em cada parede, utilizando-se da quarta parede da trincheira para o escoamento dos cabos das sondas (Figura $1)$.

A trincheira foi fechada com o mesmo solo retirado durante a sua abertura, porém, devido à diferença nas propriedades físicas do solo, as leituras só foram realizadas após período de reestruturação do solo de aproximadamente dois meses. Foram confeccionadas três trincheiras, totalizando três repetições para cada ensaio em diferentes vazões $\left(2 ; 4\right.$ e $\left.8 \mathrm{~L} \mathrm{~h}^{-1}\right)$ 


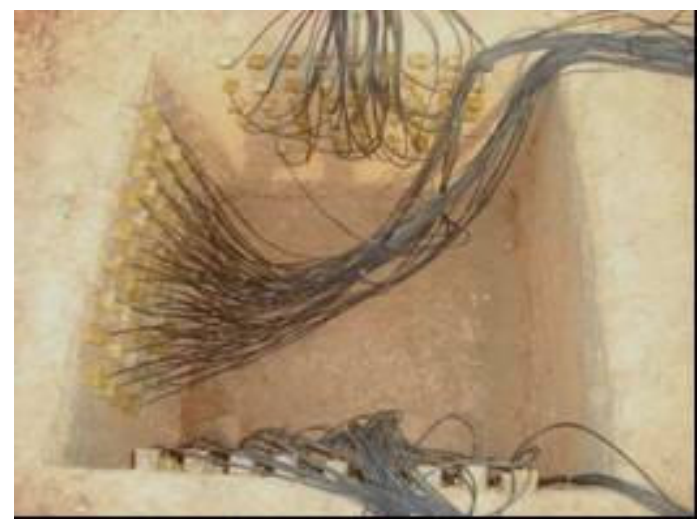

FIGURA 1. Disposição final das sondas instaladas na trincheira. Final disposition of the probes installed in the trench.

O monitoramento da dinâmica da solução no solo foi realizado por 50 sondas de TDR, em pequenos intervalos de tempo: antes da aplicação, após a infiltração e a cada meia hora após a infiltração. Instalou-se o gotejador na área central de cada parede da trincheira e utilizou-se uma vazão para cada parede, sendo $2 ; 4$ e $8 \mathrm{~L} \mathrm{~h}^{-1}$. O procedimento repetiu-se para as demais trincheiras.

Um Reflectômetro TDR100 (Campbell Scientific, Logan-Utah), equipado com uma interface RS 232, que analisa o sinal eletromagnético automaticamente por um coletor de dados (CR1000 Datalogger - Campbell Scientific), foi utilizado para o monitoramento.

As leituras de umidade e condutividade elétrica foram realizadas de forma contínua em todas as posições, acompanhando-se os ciclos de irrigação, isto é, envolvendo a fase de infiltração e a redistribuição. Assim, observou-se a formação do bulbo molhado para as vazões de $2 ; 4$ e $8 \mathrm{~L} \mathrm{~h}^{-1}$, aplicando-se $1 \mathrm{~L}$ de água a cada 1 hora, durante 10 aplicações. Um sistema com frasco de Mariote foi utilizado para manter a pressão no gotejador constante, e a aplicação do nutriente (nitrato de potássio $\mathrm{KNO}_{3}$ ) ocorreu via água de irrigação armazenada no frasco. O procedimento descrito foi desenvolvido e embasado nos trabalhos de COELHO \& OR (1999) e SOUZA et al. (2009).

O fertilizante utilizado no referido ensaio foi o nitrato de potássio $\left(\mathrm{KNO}_{3}\right)$, pois tanto o nitrogênio como o potássio apresentam grande mobilidade no solo, comportamento desejável em estudos de dinâmica de íons na solução do solo. A concentração do nutriente adicionado ao frasco foi estimada pela condutividade elétrica igual a $2 \mathrm{dS} \mathrm{m}{ }^{-1}\left(14,5 \mathrm{mmol} \mathrm{L}^{-1} \mathrm{KNO}_{3}\right)$. Este valor de condutividade elétrica foi escolhido por apresentar riscos moderados de salinidade na água de irrigação. O monitoramento do ensaio foi facilitado devido à automação das sondas de TDR por um multiplexador.

Foi possível também, a partir de uma única sonda pontual, estimar a umidade e a concentração da solução no solo. Consequentemente, a distribuição e o armazenamento da solução no solo foram monitorados e contabilizados. Estas medições foram analisadas por um programa de mapeamento superficial em 3D, o qual apresentou o perfil de distribuição do nutriente em função da umidade e condutividade elétrica do solo, proporcionando informações básicas sobre a dinâmica da solução no solo.

Para verificar o uso da técnica da TDR na estimativa da distribuição espacial e temporal da solução, amostras de solo foram coletadas no final do ensaio para a determinação da condutividade elétrica do solo $\left(\mathrm{CE}_{\mathrm{S}}\right)$ pelo método-padrão (extrato de saturação), utilizando a metodologia proposta por RICHARDS (1954).

O armazenamento da solução no solo foi contabilizado considerando-se que cada duas sondas de TDR, posicionadas simetricamente em direções opostas, representaram um anel concêntrico de solo. Desta maneira, a umidade volumétrica média de cada anel foi multiplicada pelo seu respectivo volume de solo, o que possibilitou obter volumes de água parcial e total armazenados. 
Paralelamente, obteve-se a concentração da solução no solo em mmol.L $\mathrm{L}^{-1}$, também na forma parcial ou total dentro do bulbo molhado.

Complementando o procedimento descrito acima, assumiu-se um volume central dentro do bulbo molhado de 0,40 x 0,40 x 0,50 m, respectivamente, comprimento, largura e profundidade, no qual o gotejador foi posicionado no ponto central. Desta forma, pôde-se efetuar uma análise de uniformidade comparativa, com o propósito de entender as diferenças entre os valores de umidade e de concentrações individuais estimadas dentro do volume de controle.

\section{RESULTADOS E DISCUSSÃO}

No processo de validação dos dados, obtidos durante os ensaios, verificou-se um coeficiente de correlação satisfatório $\left(\mathrm{R}^{2}=0,90\right)$ entre as leituras de condutividade elétrica obtidas com as duas

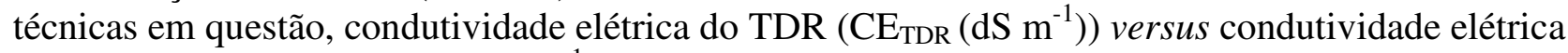

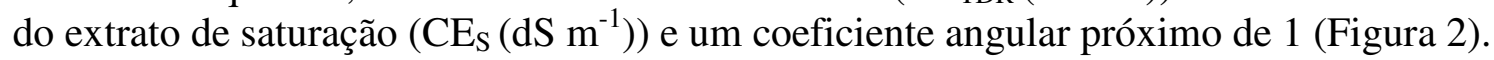

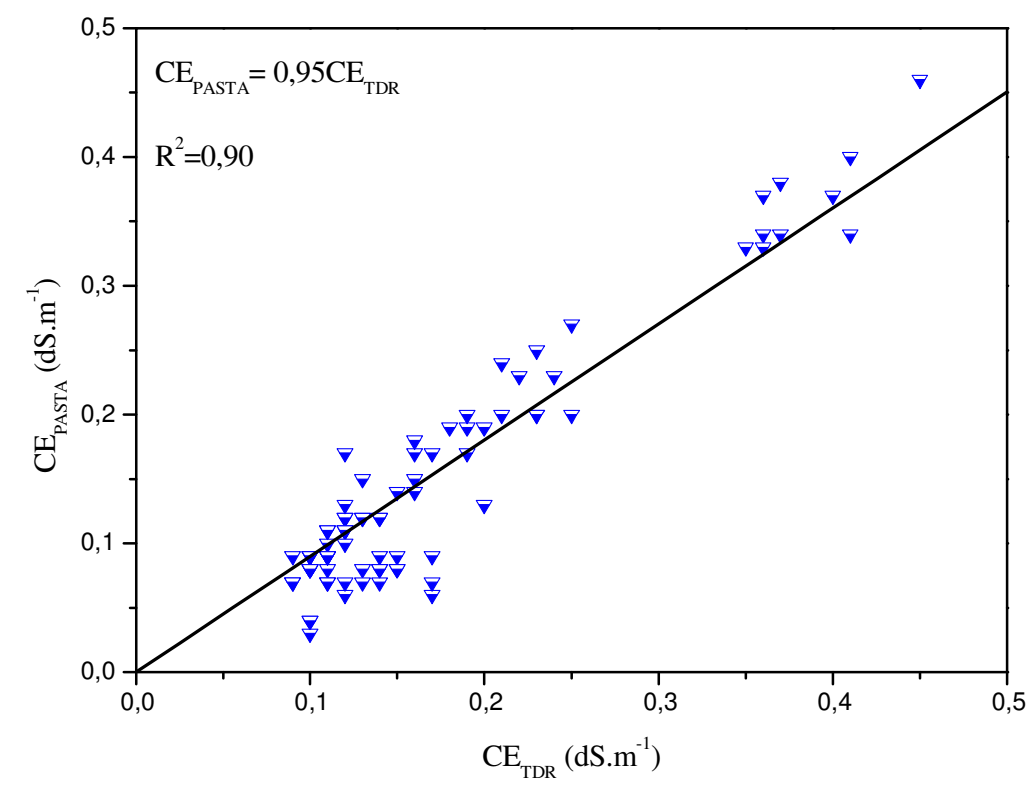

FIGURA 2. Relação entre os valores de condutividade elétrica pela técnica da TDR $\left(\mathrm{CE}_{\mathrm{TDR}}\right)$ e condutividade elétrica obtida pelo extrato de saturação $\left(\mathrm{CE}_{\mathrm{s}}\right)$. Relationship between electrical conductivity values by $T D R$ technique $\left(\mathrm{CE}_{\mathrm{TDR}}\right)$ and electrical conductivity obtained by saturation extract $\left(\mathrm{CE}_{\mathrm{s}}\right)$.

Esses resultados demonstram existir associação linear entre as técnicas e indicam variação direta no valor de $\mathrm{CE}_{\mathrm{S}}$ para uma unidade de $\mathrm{CE}_{\mathrm{TDR}}$, confirmando-se que suas características apresentam uma relação funcional na estimativa da condutividade elétrica do solo. Sendo assim, a técnica da TDR pode substituir a técnica da pasta saturada, promovendo agilidade na estimativa, sendo que o tempo envolvido na estimativa da condutividade elétrica do solo pela TDR é bem inferior à determinação feita pelo método-padrão (extrato de saturação).

Para relacionar $\mathrm{CE}_{\mathrm{TDR}}$ com $\mathrm{CE}_{\mathrm{S}}$, utilizou-se a equação descrita por SOUZA et al. (2006b), como segue:

$$
\mathrm{CE}_{\mathrm{S}}=\frac{\mathrm{CE}_{\mathrm{TDR}}-0,04}{(2,61 \theta-0,16) \theta}
$$

em que,

$\theta$ - umidade volumétrica, $\mathrm{m}^{3} \mathrm{~m}^{-3}$.

Nas Figuras 3; 4 e 5, foram analisados os perfis de umidade $\left(\mathrm{m}^{3} \mathrm{~m}^{-3}\right)$ do solo para diferentes vazões $\left(2,4\right.$ e $\left.8 \mathrm{~L} \mathrm{~h}^{-1}\right)$, observados durante dez aplicações da solução de nitrato de potássio $\left(\mathrm{KNO}_{3}\right)$ no solo. 


\section{Distância do Gotejador (cm)}

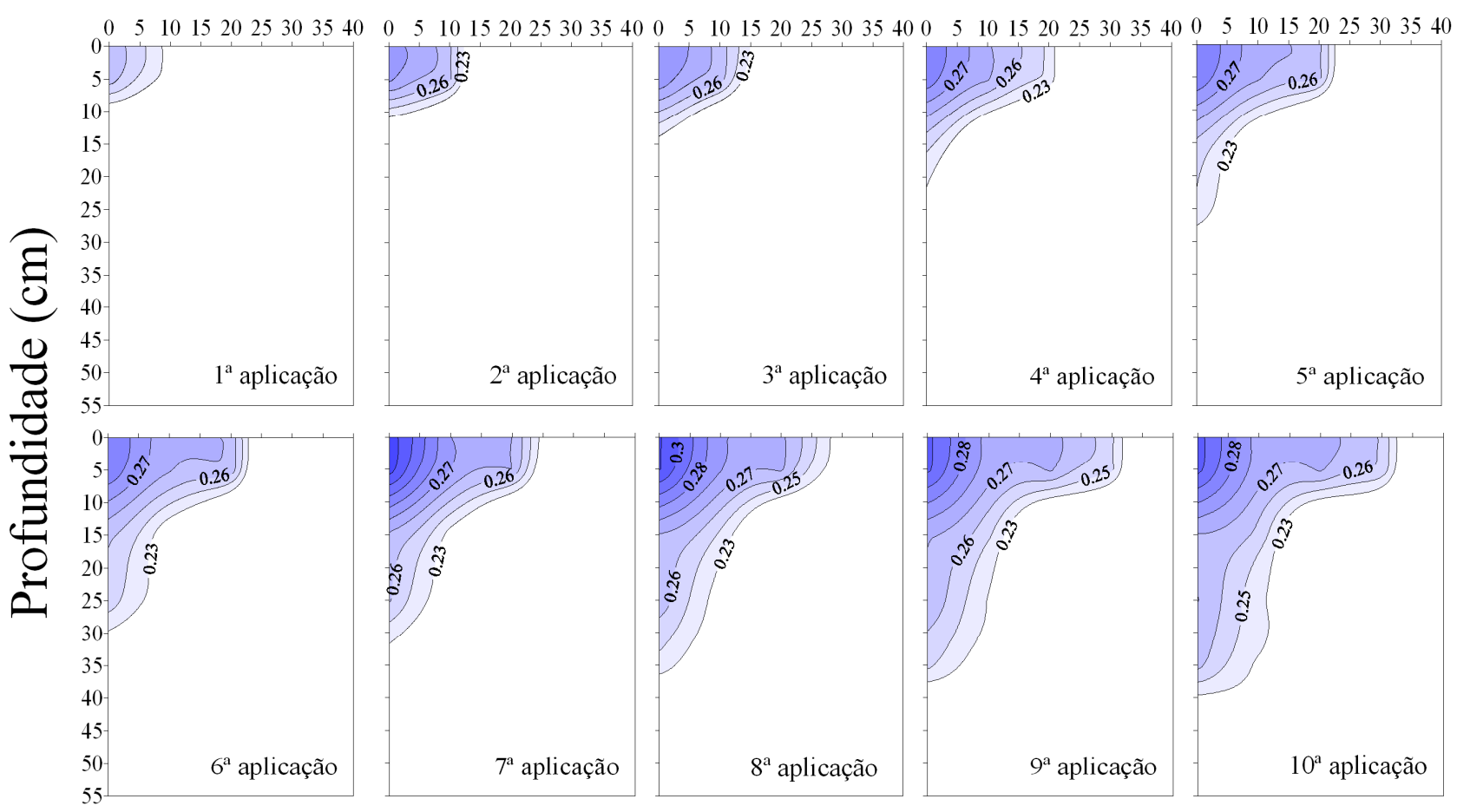

FIGURA 3. Perfis de umidade do solo $\left(\mathrm{m}^{3} \mathrm{~m}^{-3}\right)$ ao final do processo de infiltração de cada aplicação de $\mathrm{KNO}_{3}$ para vazão de $2 \mathrm{~L} \mathrm{~h}^{-1}$. Soil water content profiles $\left(\mathrm{m}^{3} \mathbf{m}^{-3}\right)$ at the end of the infiltration process of each $\mathrm{KNO}_{3}$ application at a flow rate of $2 \mathrm{~L} \mathrm{~h}^{-1}$.

\section{Distância do Gotejador (cm)}

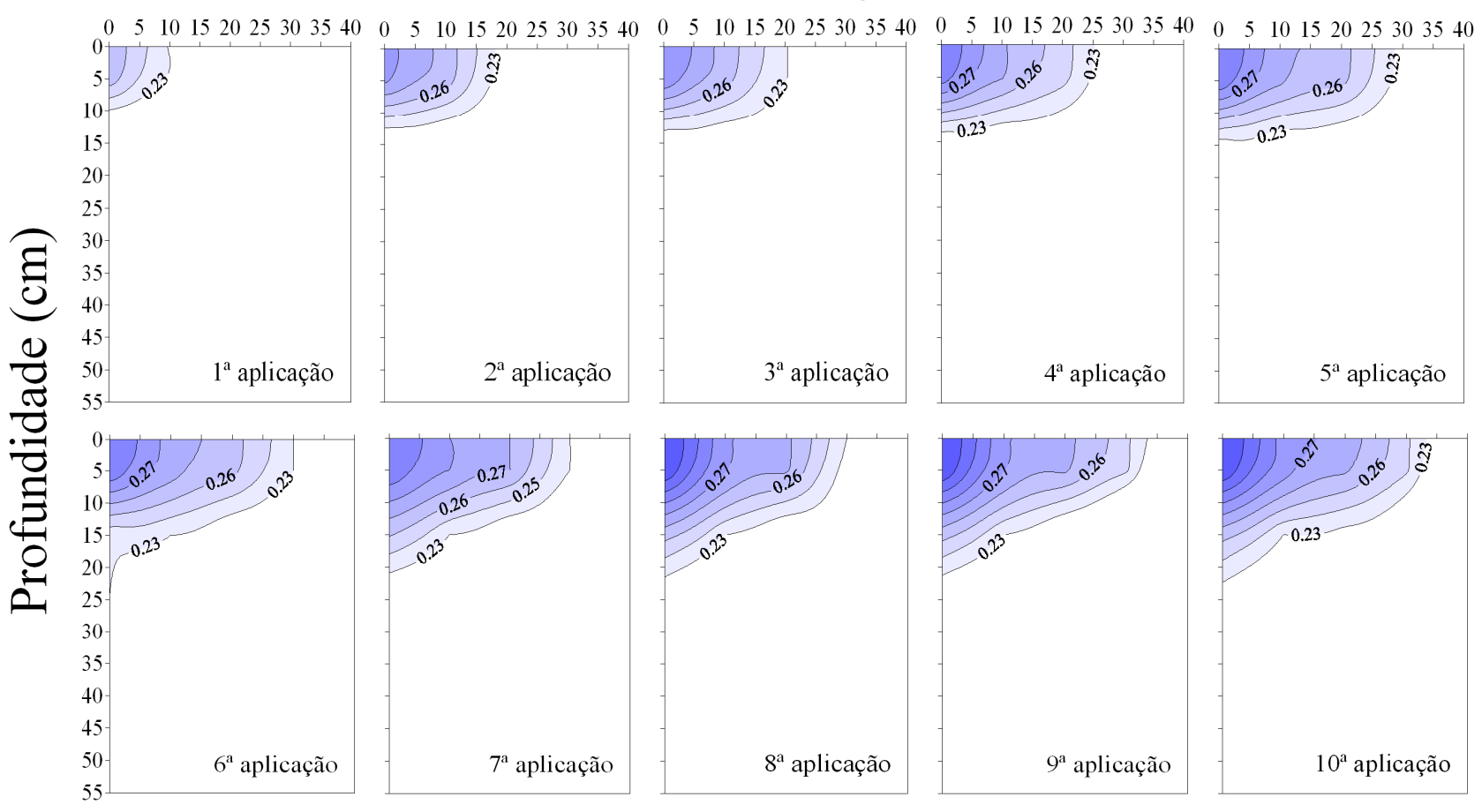

FIGURA 4. Perfis de umidade do solo $\left(\mathrm{m}^{3} \mathrm{~m}^{-3}\right)$ ao final do processo de infiltração de cada aplicação de $\mathrm{KNO}_{3}$ para vazão de $4 \mathrm{~L} \mathrm{~h}^{-1}$. Soil water content profiles $\left(\mathbf{m}^{3} \mathbf{~ m}^{-3}\right)$ at the end of the infiltration process of each $\mathrm{KNO}_{3}$ application at a flow rate of $4 \mathrm{~L} \mathrm{~h}^{-1}$. 


\section{Distância do Gotejador (cm)}

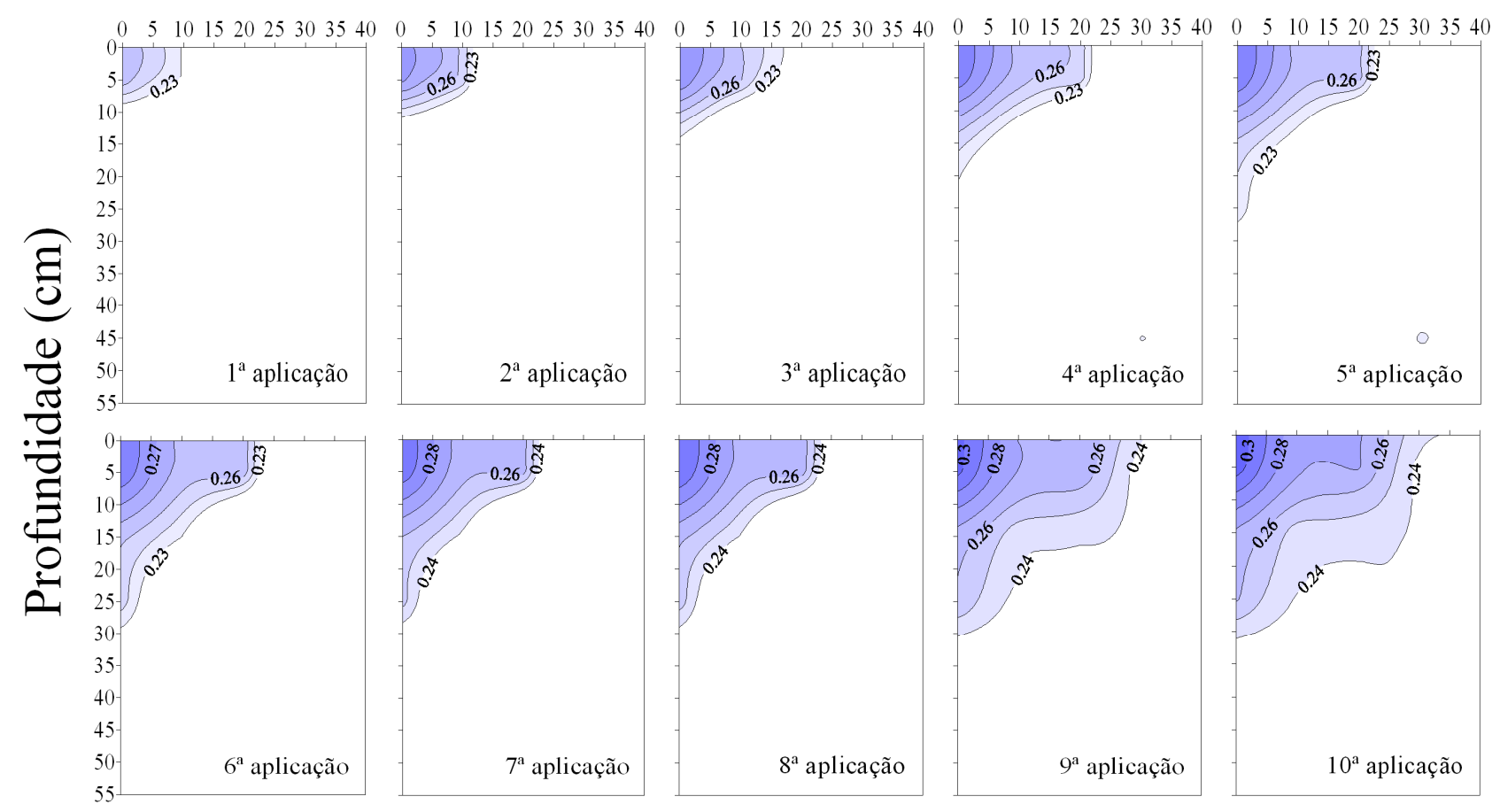

FIGURA 5. Perfis de umidade do solo $\left(\mathrm{m}^{3} \mathrm{~m}^{-3}\right)$ ao final do processo de infiltração de cada aplicação de $\mathrm{KNO}_{3}$ para vazão de $8 \mathrm{~L} \mathrm{~h}^{-1}$. Soil water content profiles $\left(\mathrm{m}^{3} \mathbf{~ m}^{-3}\right)$ at the end of the infiltration process of each $\mathrm{KNO}_{3}$ application at a flow rate of $8 \mathrm{~L} \mathrm{~h}^{-1}$.

Por tratar-se a técnica da TDR como sendo um método indireto para estimar a umidade volumétrica do solo $(\theta)$, utilizou-se uma equação de calibração para a conversão da constante dielétrica aparente $(\mathrm{Ka})$ em umidade volumétrica do solo, proposta por ALMEIDA et al. (2007) para o mesmo solo e local de estudo.

$$
\theta=910^{-5} \mathrm{Ka}^{3}-0,038 \mathrm{Ka}^{2}+0,0577 \mathrm{Ka}-0,0484
$$

em que,

$\mathrm{Ka}$ - constante dielétrica aparente.

Conforme os resultados experimentais de umidade obtidos com as leituras do aparelho de TDR, observou-se, nas primeiras aplicações, que os teores de água no perfil do solo se mostraram simétricos nos eixos vertical e horizontal. Sendo que, com a continuidade das aplicações de solução no solo, teve-se um aumento gradativo da umidade do solo enquanto a frente de umedecimento evoluía. Verificou-se, também, maior armazenamento da solução próximo ao gotejador e, consequentemente diminuição desta, à medida que se aproxima da frente de molhamento. Resultados semelhantes foram encontrados por SOUZA et al. (2009) em ensaio de laboratório e LOPES et al. (2009) em ensaios de campo.

Têm-se, pela Figura 3, os perfis de umidade do solo para a vazão de $2 \mathrm{~L} \mathrm{~h}^{-1}$, em dez aplicações da solução a cada hora. Verificou-se que, nas primeiras aplicações, houve simetria na evolução do bulbo no sentido vertical em relação ao horizontal, no perfil do solo, ocorrendo maior aumento no sentido vertical somente após a quinta aplicação. Observou-se ainda que, durante as dez aplicações nesta vazão $\left(2 \mathrm{~L} \mathrm{~h}^{-1}\right)$ não se ultrapassou a profundidade de $0,40 \mathrm{~m}$.

Os perfis de umidade do solo para vazão de $4 \mathrm{~L} \mathrm{~h}^{-1}$ (Figura 4), se comparados à de $2 \mathrm{~L} \mathrm{~h}^{-1}$ (Figura 3), apresentaram uma mobilidade vertical evoluindo em menor proporção, não ultrapassando a profundidade de 0,23 m após a décima aplicação. Porém, no sentido horizontal, a 
frente de umedecimento evoluiu rapidamente, verificando-se que logo após a quarta aplicação se manteve no intervalo entre $0,25 \mathrm{~m}$ e $0,33 \mathrm{~m}$, até a décima aplicação de solução.

Comparando os bulbos de umidade do solo, percebeu-se que, com a aplicação do dobro da vazão (de 2 para $4 \mathrm{~L} \mathrm{~h}^{-1}$ ), foram proporcionadas maiores dimensões do bulbo molhado na horizontal e diminuição no sentido vertical. Estes resultados corroboram as observações feitas por LOPES et al. (2009) para as mesmas vazões e tipo de solo, e com os resultados obtidos por SOUZA \& MATSURA (2004) em Latossolo Vermelho distroférrico.

Os autores verificaram que, aumentando-se a vazão do gotejador, observou-se aumento no raio horizontal e, diminuindo-se a vazão, ocorre acréscimo no raio vertical do bulbo molhado, devido à alteração da área de infiltração da água aplicada. Esses mesmos autores relatam, ainda, que esses resultados estão em concordância com experimentos realizados por BRESLER et al. (1971), BRESLER (1978), SCHWARTZMAN \& ZUR (1986) e KELLER \& BLIESNER (1990), os quais concluem que um aumento na vazão do gotejador resulta em um acréscimo no movimento horizontal e uma expansão menor no movimento vertical da água no bulbo.

Na vazão de $8 \mathrm{~L} \mathrm{~h}^{-1}$, conforme Figura 5 , dos perfis de umidade, verificou-se semelhança quanto ao movimento da água nos diferentes eixos (vertical e horizontal). Nesta vazão, houve uma distribuição da umidade semelhante à dos bulbos de $4 \mathrm{~L} \mathrm{~h}^{-1}$, porém com maior evolução vertical, mostrando-se, assim, intermediário entre os bulbos de umidade de $2 \mathrm{~L} \mathrm{~h}^{-1} \mathrm{e} 4 \mathrm{~L} \mathrm{~h}^{-1}$. SOUZA et al. (2006c), em experimento realizado em laboratório para as mesmas vazões $\left(2 ; 4 \mathrm{e}^{2} \mathrm{~L} \mathrm{~h}^{-1}\right)$,

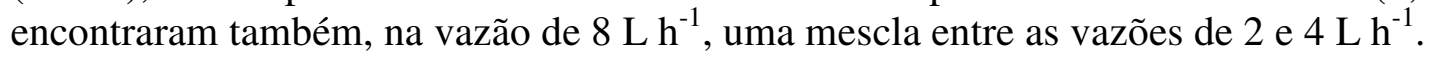

Neste mesmo ensaio, foi possível comparar os perfis de condutividade elétrica $\left(\mathrm{dS} \mathrm{m}^{-1}\right)$ nas estimativas feitas pela técnica de TDR após cada aplicação de nitrato de potássio $\left(\mathrm{KNO}_{3}\right)$ no solo, sendo 10 aplicações para as vazões de $2 ; 4$ e $8 \mathrm{~L} \mathrm{~h}^{-1}$.

Os perfis de CE das Figuras 6; 7 e 8 apresentaram uma relação de formato e tamanho próximo dos perfis de umidade para as diferentes vazões. No entanto, a maioria dos perfis de CE manteve-se com tamanho um pouco inferior ao dos perfis de umidade do solo para as vazões de $2 ; 4$ e $8 \mathrm{~L} \mathrm{~h}^{-1}$. Uma hipótese para este fenômeno pode ser baseada no fato de que os íons acompanham a frente de avanço da água, sendo que esta se movimenta um pouco à frente dos sais, em direção ao extremo do bulbo.

Conforme VALOCCHI (1984) e BLANCO \& FOLLEGATI (2001), os sais movimentam-se mais lentamente no solo do que à frente de avanço da água (fluxo de massa), o que proporcionará uma distribuição heterogênea da concentração destes.

Outra hipótese, segundo RIVERA et al. (2006), está baseada na CTC (capacidade de troca catiônica) do solo, ou seja, o potássio da solução do solo interagiu com o complexo de troca de cátions, sendo, portanto, este elemento retido no solo na região mais próxima do ponto de aplicação, de forma que a solução que se deslocou para as regiões mais extremas do bulbo molhado possuía uma concentração iônica menor.

Comparando os sistemas de menor vazão $\left(2 \mathrm{~L} \mathrm{~h}^{-1}\right)$ com os de maiores vazões $\left(4 \mathrm{e} 8 \mathrm{~L} \mathrm{~h}^{-1}\right)$ nos perfis de CE, verificou-se que, na menor vazão, os sais são disponibilizados a uma distância (vertical) bem superior de ponto de emissão, sendo que esta diferença não foi observada nos sistemas de vazões superiores.

Levando-se em consideração o manejo da fertirrigação, notou-se que, no sistema de menor vazão $\left(2 \mathrm{~L} \mathrm{~h}^{-1}\right)$, houve uma tendência de perda de nutrientes por lixiviação, dado este importante, já que o consumo (aplicação) de nutrientes ao solo tem relação direta tanto no custo de produção, quanto ao impacto ambiental causado pela lixiviação dos sais para os corpos d'água. 


\section{Distância do Gotejador (cm)}

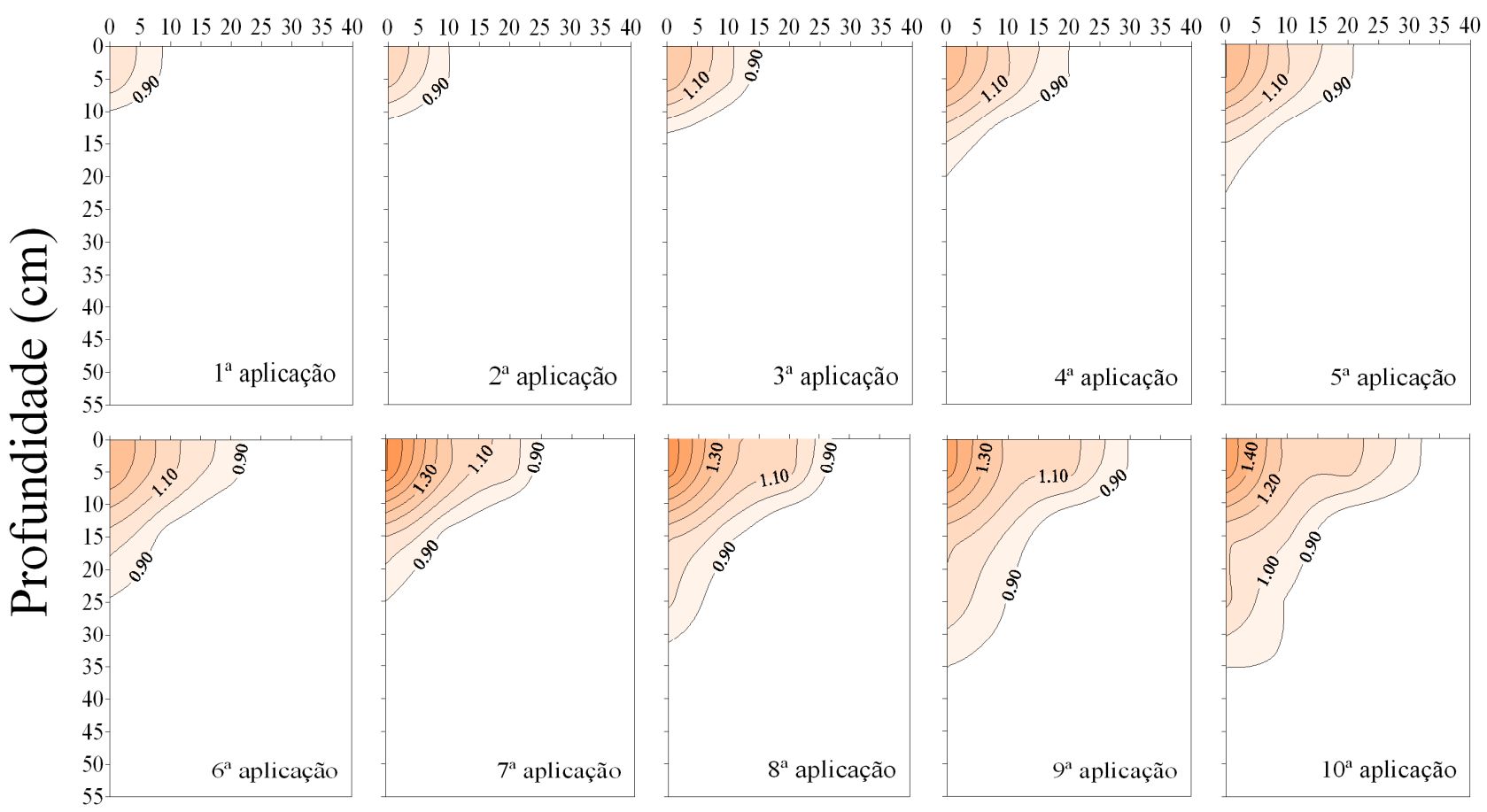

FIGURA 6. Perfis de condutividade elétrica do solo $\left(\mathrm{dS} \mathrm{m}^{-1}\right)$ ao final do processo de infiltração de cada aplicação da solução de $\mathrm{KNO}_{3}$ para vazão de $2 \mathrm{~L} \mathrm{~h}^{-1}$. Soil electrical conductivity profiles $\left(\mathrm{dS} \mathrm{m}^{-1}\right)$ at the end of the infiltration process of each $\mathrm{KNO}_{3}$ application at a flow rate of $2 \mathrm{~L} \mathrm{~h}^{-1}$.

\section{Distância do Gotejador $(\mathrm{cm})$}

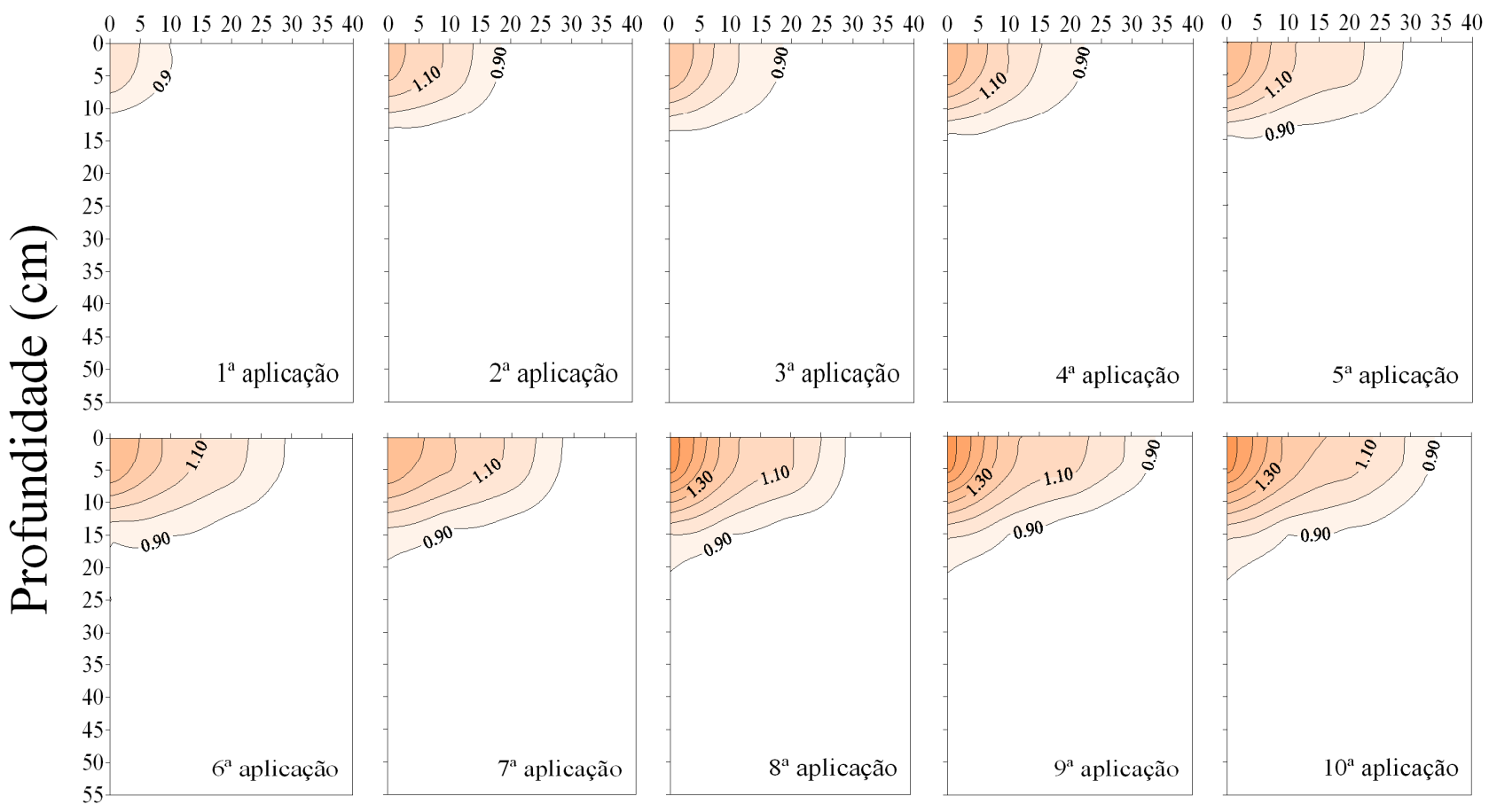

FIGURA 7. Perfis de condutividade elétrica do solo $\left(\mathrm{dS} \mathrm{m}^{-1}\right)$ ao final do processo de infiltração de cada aplicação da solução de $\mathrm{KNO}_{3}$ para vazão de $4 \mathrm{~L} \mathrm{~h}^{-1}$. Soil electrical conductivity profiles $\left(\mathrm{dS} \mathrm{m}^{-1}\right)$ at the end of the infiltration process of each $\mathrm{KNO}_{3}$ application at a flow rate of $4 \mathrm{~L} \mathrm{~h}^{-1}$. 


\section{Distância do Gotejador (cm)}

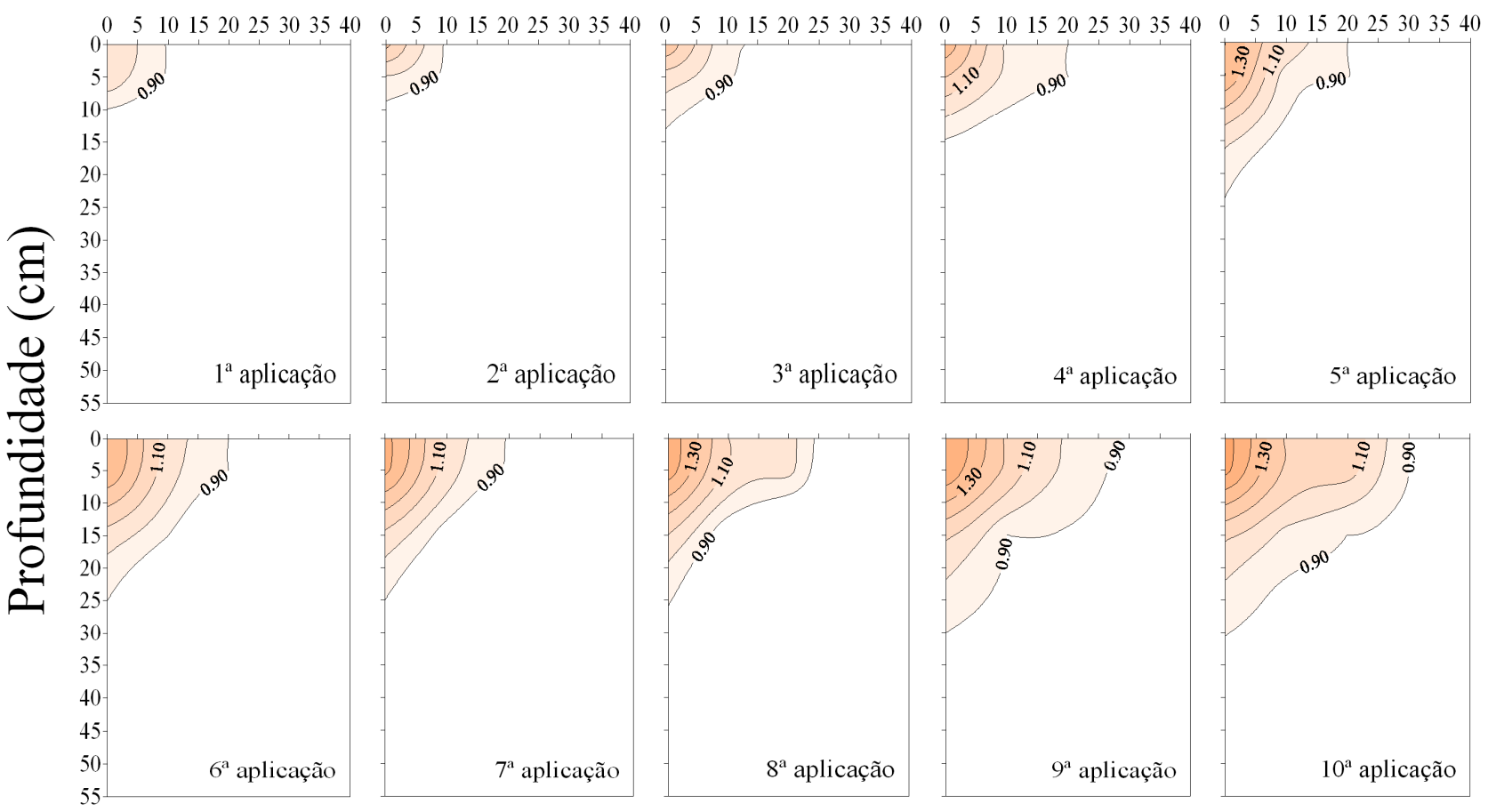

FIGURA 8. Perfis de condutividade elétrica do solo $\left(\mathrm{dS} \mathrm{m}^{-1}\right)$ ao final do processo de infiltração de cada aplicação da solução de $\mathrm{KNO}_{3}$ para vazão de $8 \mathrm{~L} \mathrm{~h}^{-1}$. Soil electrical conductivity profiles $\left(\mathrm{dS} \mathrm{m}^{-1}\right)$ at the end of the infiltration process of each KNO3 application at a flow rate of $8 \mathrm{~L} \mathrm{~h}^{-1}$.

Identificaram-se também, neste ensaio, o armazenamento do volume da solução e a concentração da solução no perfil do solo estudado. Na Tabela 2, têm-se os volumes de distribuição da solução no solo, verificando-se que houve maior armazenamento da solução na camada de 0$0,10 \mathrm{~m}$, desde a primeira até a décima aplicação da solução no solo, nas diferentes vazões $(2 ; 4 \mathrm{e}$ $\left.8 \mathrm{~L} \mathrm{~h}^{-1}\right)$, e que nesta camada $(0-0,10 \mathrm{~m})$, o maior armazenamento do volume de solução ocorreu na vazão de $4 \mathrm{~L} \mathrm{~h}^{-1}$. Estes resultados também foram encontrados por SOUZA et al. (2009) em ensaios de laboratório para as mesmas vazões e tipo de solo.

Observou-se ainda que somente na vazão de $4 \mathrm{~L} \mathrm{~h}^{-1}$ a solução não atingiu a camada de 0,30 -0,40 m, demonstrando que o armazenamento do volume da solução manteve-se nas camadas superiores do perfil do solo. Em contrapartida, na vazão de $2 \mathrm{~L} \mathrm{~h}^{-1}$, a camada de 0,4-0,5 m foi atingida na décima aplicação da solução no solo, o que demonstra uma tendência à lixiviação dos nutrientes nesta vazão. No monitoramento do ensaio com vazão de $8 \mathrm{~L} \mathrm{~h}^{-1}$, verificou-se que somente após a sétima aplicação a solução atingiu a camada de solo de 0,30-0,40 m. Desta forma, pode-se notar que a relação entre o armazenamento e a taxa de aplicação, nas vazões de 4 e $8 \mathrm{~L} \mathrm{~h}^{-1}$, apresentou tendência em aumentar a distribuição do volume da solução em camadas superiores, $o$ que não ocorreu na vazão de $2 \mathrm{~L} \mathrm{~h}^{-1}$.

Na Tabela 3, tem-se a concentração da solução para o perfil de distribuição do solo, notando-se que, assim como nos resultados dos dados da Tabela 2, durante todas as aplicações, a maior concentração da solução no perfil do solo também ocorreu na camada de $0-0,10 \mathrm{~m}$, nas diferentes vazões $\left(2 ; 4\right.$ e $\left.8 \mathrm{~L} \mathrm{~h}^{-1}\right)$, e que entre essas vazões aplicadas a maior concentração da solução foi na vazão de $4 \mathrm{~L} \mathrm{~h}^{-1}$. Observou-se também, nas Tabelas 2 e 3 (volume versus concentração da solução), uma distribuição em gradiente da solução no perfil do solo estudado, sendo que houve maior concentração da solução próxima ao gotejador. 
TABELA 2. Estimativa do volume da solução para o perfil de distribuição no solo. Estimated volume of solution for the soil distribution profile.

\begin{tabular}{|c|c|c|c|c|c|c|c|c|c|}
\hline \multirow{3}{*}{ Aplicações } & \multirow{3}{*}{$\begin{array}{c}\text { Volume } \\
\text { acumulado } \\
\text { medido }\end{array}$} & \multirow{3}{*}{$\begin{array}{l}\text { Volume } \\
\text { parcial } \\
\text { medido }\end{array}$} & \multicolumn{6}{|c|}{ Distribuição da solução } & \multirow{3}{*}{$\begin{array}{c}\text { CUC } \\
(\%)\end{array}$} \\
\hline & & & \multicolumn{6}{|c|}{ Camadas (m) } & \\
\hline & & & $0-0,1$ & $0,1-0,2$ & $0,2-0,3$ & $0,3-0,4$ & $0,4-0,5$ & $0,5-0,6$ & \\
\hline \multicolumn{10}{|c|}{ Volume (L) } \\
\hline \multicolumn{10}{|l|}{$2 \mathrm{~L} \mathrm{~h}^{-1}$} \\
\hline $1^{\mathrm{a}}$ & 0,97 & 0,97 & 0,81 & 0,16 & 0,00 & 0,00 & 0,00 & 0,00 & 90 \\
\hline $2^{a}$ & 1,96 & 0,99 & 0,80 & 0,19 & 0,00 & 0,00 & 0,00 & 0,00 & 91 \\
\hline $3^{\mathrm{a}}$ & 2,92 & 0,96 & 0,71 & 0,25 & 0,00 & 0,00 & 0,00 & 0,00 & 90 \\
\hline $4^{\mathrm{a}}$ & 3,88 & 0,96 & 0,64 & 0,27 & 0,05 & 0,00 & 0,00 & 0,00 & 90 \\
\hline $5^{\mathrm{a}}$ & 4,83 & 0,95 & 0,56 & 0,21 & 0,18 & 0,00 & 0,00 & 0,00 & 90 \\
\hline $6^{\mathrm{a}}$ & 5,82 & 0,99 & 0,57 & 0,19 & 0,18 & 0,05 & 0,00 & 0,00 & 89 \\
\hline $7^{a}$ & 6,79 & 0,97 & 0,49 & 0,23 & 0,17 & 0,08 & 0,00 & 0,00 & 88 \\
\hline $8^{a}$ & 7,74 & 0,95 & 0,44 & 0,19 & 0,18 & 0,14 & 0,00 & 0,00 & 89 \\
\hline $9^{a}$ & 8,68 & 0,94 & 0,41 & 0,20 & 0,19 & 0,14 & 0,00 & 0,00 & 89 \\
\hline $10^{\mathrm{a}}$ & 9,62 & 0,94 & 0,40 & 0,19 & 0,17 & 0,14 & 0,04 & 0,00 & 89 \\
\hline \multicolumn{10}{|l|}{$4 \mathrm{~L} \mathrm{~h}^{-1}$} \\
\hline $1^{\mathrm{a}}$ & 0,95 & 0,95 & 0,90 & 0,05 & 0,00 & 0,00 & 0,00 & 0,00 & 95 \\
\hline $2^{a}$ & 1,90 & 0,95 & 0,80 & 0,15 & 0,00 & 0,00 & 0,00 & 0,00 & 96 \\
\hline $3^{a}$ & 2,88 & 0,98 & 0,80 & 0,18 & 0,00 & 0,00 & 0,00 & 0,00 & 96 \\
\hline $4^{a}$ & 3,84 & 0,96 & 0,72 & 0,24 & 0,00 & 0,00 & 0,00 & 0,00 & 95 \\
\hline $5^{a}$ & 4,80 & 0,96 & 0,70 & 0,26 & 0,00 & 0,00 & 0,00 & 0,00 & 95 \\
\hline $6^{\mathrm{a}}$ & 5,75 & 0,95 & 0,64 & 0,27 & 0,04 & 0,00 & 0,00 & 0,00 & 95 \\
\hline $7^{a}$ & 6,70 & 0,95 & 0,65 & 0,23 & 0,07 & 0,00 & 0,00 & 0,00 & 95 \\
\hline $8^{a}$ & 7,67 & 0,97 & 0,59 & 0,29 & 0,09 & 0,00 & 0,00 & 0,00 & 94 \\
\hline $9^{a}$ & 8,66 & 0,99 & 0,60 & 0,30 & 0,09 & 0,00 & 0,00 & 0,00 & 94 \\
\hline $10^{\mathrm{a}}$ & 9,60 & 0,94 & 0,53 & 0,28 & 0,13 & 0,00 & 0,00 & 0,00 & 94 \\
\hline \multicolumn{10}{|l|}{$8 \mathrm{~L} \mathrm{~h}^{-1}$} \\
\hline $1^{\mathrm{a}}$ & 0,98 & 0,98 & 0,90 & 0,08 & 0,00 & 0,00 & 0,00 & 0,00 & 94 \\
\hline $2^{a}$ & 1,96 & 0,98 & 0,87 & 0,11 & 0,00 & 0,00 & 0,00 & 0,00 & 92 \\
\hline $3^{a}$ & 2,92 & 0,96 & 0,73 & 0,23 & 0,00 & 0,00 & 0,00 & 0,00 & 92 \\
\hline $4^{a}$ & 3,88 & 0,96 & 0,66 & 0,23 & 0,07 & 0,00 & 0,00 & 0,00 & 92 \\
\hline $5^{a}$ & 4,87 & 0,99 & 0,59 & 0,27 & 0,13 & 0,00 & 0,00 & 0,00 & 92 \\
\hline $6^{a}$ & 5,85 & 0,98 & 0,55 & 0,23 & 0,20 & 0,00 & 0,00 & 0,00 & 93 \\
\hline $7^{a}$ & 6,80 & 0,95 & 0,51 & 0,21 & 0,19 & 0,04 & 0,00 & 0,00 & 93 \\
\hline $8^{a}$ & 7,74 & 0,94 & 0,46 & 0,22 & 0,17 & 0,09 & 0,00 & 0,00 & 93 \\
\hline $9^{a}$ & 8,69 & 0,95 & 0,43 & 0,21 & 0,19 & 0,12 & 0,00 & 0,00 & 93 \\
\hline $10^{\mathrm{a}}$ & 9,65 & 0,96 & 0,41 & 0,20 & 0,20 & 0,15 & 0,00 & 0,00 & 93 \\
\hline
\end{tabular}


TABELA 3. Estimativa da concentração da solução para o perfil de distribuição no solo. Estimated concentration of solution for the soil distribution profile.

\begin{tabular}{|c|c|c|c|c|c|c|c|c|c|}
\hline \multirow{3}{*}{ Aplicações } & \multirow{3}{*}{$\begin{array}{l}\text { Concentra- } \\
\text { ção } \\
\text { acumulada } \\
\text { medida } \\
\end{array}$} & \multirow{3}{*}{$\begin{array}{c}\text { Concen- } \\
\text { tração } \\
\text { parcial } \\
\text { medida }\end{array}$} & \multicolumn{6}{|c|}{ Distribuição da solução } & \multirow{3}{*}{$\begin{array}{c}\text { CUC } \\
(\%)\end{array}$} \\
\hline & & & \multicolumn{6}{|c|}{ Camadas (m) } & \\
\hline & & & $0-0,1$ & $0,1-0,2$ & $0,2-0,3$ & $0,3-0,4$ & $0,4-0,5$ & $0,5-0,6$ & \\
\hline \multicolumn{10}{|c|}{ Concentração $\left(\mathrm{mmoL} \mathrm{L}^{-1}\right)$} \\
\hline \multicolumn{10}{|l|}{$2 \mathrm{~L} \mathrm{~h}^{-1}$} \\
\hline $1^{\mathrm{a}}$ & 0,59 & 0,59 & 0,56 & 0,03 & 0,00 & 0,00 & 0,00 & 0,00 & 86 \\
\hline $2^{a}$ & 1,24 & 0,65 & 0,55 & 0,10 & 0,00 & 0,00 & 0,00 & 0,00 & 87 \\
\hline $3^{a}$ & 2,04 & 0,80 & 0,50 & 0,30 & 0,00 & 0,00 & 0,00 & 0,00 & 87 \\
\hline $4^{\mathrm{a}}$ & 2,40 & 0,36 & 0,20 & 0,10 & 0,06 & 0,00 & 0,00 & 0,00 & 86 \\
\hline $5^{a}$ & 2,84 & 0,44 & 0,20 & 0,15 & 0,09 & 0,00 & 0,00 & 0,00 & 87 \\
\hline $6^{a}$ & 3,36 & 0,52 & 0,23 & 0,17 & 0,09 & 0,03 & 0,00 & 0,00 & 85 \\
\hline $7^{\mathrm{a}}$ & 4,16 & 0,80 & 0,39 & 0,23 & 0,10 & 0,08 & 0,00 & 0,00 & 83 \\
\hline $8^{a}$ & 4,48 & 0,32 & 0,10 & 0,10 & 0,07 & 0,05 & 0,00 & 0,00 & 83 \\
\hline $9^{a}$ & 4,89 & 0,41 & 0,20 & 0,10 & 0,06 & 0,05 & 0,00 & 0,00 & 82 \\
\hline $10^{\mathrm{a}}$ & 5,35 & 0,46 & 0,19 & 0,10 & 0,09 & 0,06 & 0,02 & 0,00 & 81 \\
\hline \multicolumn{10}{|l|}{$4 \mathrm{~L} \mathrm{~h}^{-1}$} \\
\hline $1^{\mathrm{a}}$ & 0,82 & 0,82 & 0,60 & 0,22 & 0,00 & 0,00 & 0,00 & 0,00 & 88 \\
\hline $2^{\mathrm{a}}$ & 1,73 & 0,91 & 0,59 & 0,32 & 0,00 & 0,00 & 0,00 & 0,00 & 88 \\
\hline $3^{a}$ & 2,06 & 0,33 & 0,20 & 0,13 & 0,00 & 0,00 & 0,00 & 0,00 & 89 \\
\hline $4^{a}$ & 2,75 & 0,69 & 0,49 & 0,20 & 0,00 & 0,00 & 0,00 & 0,00 & 87 \\
\hline $5^{a}$ & 3,35 & 0,60 & 0,38 & 0,22 & 0,00 & 0,00 & 0,00 & 0,00 & 86 \\
\hline $6^{\mathrm{a}}$ & 3,65 & 0,30 & 0,15 & 0,10 & 0,05 & 0,00 & 0,00 & 0,00 & 86 \\
\hline $7^{\mathrm{a}}$ & 4,02 & 0,37 & 0,17 & 0,13 & 0,07 & 0,00 & 0,00 & 0,00 & 83 \\
\hline $8^{a}$ & 4,84 & 0,82 & 0,50 & 0,23 & 0,09 & 0,00 & 0,00 & 0,00 & 81 \\
\hline $9^{a}$ & 5,20 & 0,36 & 0,17 & 0,10 & 0,09 & 0,00 & 0,00 & 0,00 & 80 \\
\hline $10^{\mathrm{a}}$ & 5,53 & 0,33 & 0,15 & 0,13 & 0,05 & 0,00 & 0,00 & 0,00 & 81 \\
\hline \multicolumn{10}{|l|}{$8 \mathrm{~L} \mathrm{~h}^{-1}$} \\
\hline $1^{\mathrm{a}}$ & 0,74 & 0,74 & 0,64 & 0,10 & 0,00 & 0,00 & 0,00 & 0,00 & 86 \\
\hline $2^{\mathrm{a}}$ & 1,36 & 0,62 & 0,51 & 0,11 & 0,00 & 0,00 & 0,00 & 0,00 & 86 \\
\hline $3^{a}$ & 1,72 & 0,36 & 0,20 & 0,16 & 0,00 & 0,00 & 0,00 & 0,00 & 85 \\
\hline $4^{\mathrm{a}}$ & 2,14 & 0,42 & 0,22 & 0,17 & 0,03 & 0,00 & 0,00 & 0,00 & 83 \\
\hline $5^{a}$ & 2,51 & 0,37 & 0,22 & 0,10 & 0,05 & 0,00 & 0,00 & 0,00 & 82 \\
\hline $6^{\mathrm{a}}$ & 3,34 & 0,83 & 0,37 & 0,25 & 0,21 & 0,00 & 0,00 & 0,00 & 81 \\
\hline $7^{\mathrm{a}}$ & 3,91 & 0,57 & 0,20 & 0,19 & 0,16 & 0,02 & 0,00 & 0,00 & 82 \\
\hline $8^{a}$ & 4,33 & 0,42 & 0,17 & 0,11 & 0,09 & 0,05 & 0,00 & 0,00 & 83 \\
\hline $9^{a}$ & 4,85 & 0,52 & 0,19 & 0,14 & 0,10 & 0,09 & 0,00 & 0,00 & 82 \\
\hline $10^{\mathrm{a}}$ & 5,23 & 0,38 & 0,15 & 0,10 & 0,08 & 0,05 & 0,00 & 0,00 & 82 \\
\hline
\end{tabular}

Tendo como propósito entender as diferenças entre os valores de umidade individual estimada dentro de um volume de controle, assumiu-se um volume de solo central no bulbo molhado para efetuar uma análise de uniformidade de distribuição comparativa. Desta forma, foi possível calcular os coeficientes de uniformidade de CHRISTIANSEN (1941) para as umidades estimadas após cada aplicação da solução, nas vazões de 2; 4 e $8 \mathrm{~L} \mathrm{~h}^{-1}$, seguindo-se a metodologia adaptada por WU \& GITLIN (1983) e OULD MOHAMED EL-HAFEDH et al. (2001), por meio da eq.(3): 


$$
\mathrm{CUC}=100\left[1-\frac{\Sigma\left|\mathrm{X}_{\mathrm{i}}-\overline{\mathrm{X}}\right|}{\mathrm{XN}}\right]
$$

em que,

CUC - coeficiente de uniformidade de distribuição de Christiansenm \%;

$\mathrm{X}_{\mathrm{i}}$ - umidade volumétrica estimada, $\mathrm{m}^{3} \mathrm{~m}^{-3}$;

$\mathrm{X}$ - umidade volumétrica média, $\mathrm{m}^{3} \mathrm{~m}^{-3}$, e

$\mathrm{N}$ - número de pontos estimados.

$\mathrm{O}$ volume de controle adotado foi $0,40 \times 0,40 \times 0,50 \mathrm{~m}$, respectivamente, comprimento, largura e profundidade, sendo o gotejador posicionado no ponto central da parede da trincheira.

Fazendo-se uma análise comparativa entre as vazões adotadas, notou-se que, na vazão de $2 \mathrm{~L} \mathrm{~h}^{-1}$, os valores de uniformidade mostraram-se inferiores aos da vazão de 4 e $8 \mathrm{~L} \mathrm{~h}^{-1}$ durante todas as aplicações (Tabela 2). O coeficiente de uniformidade (CUC) na vazão de $2 \mathrm{~L} \mathrm{~h}^{-1}$ mantevese entre $88 \%$ e $90 \%$, desde a primeira até a décima aplicação, tendo um ligeiro decréscimo no decorrer das aplicações, porém não teve grande variação se comparado com a média de uniformidade das vazões (92\%). No entanto, verifica-se que, com o aumento da vazão de $2 \mathrm{~L} \mathrm{~h}^{-1}$ para $4 \mathrm{~L} \mathrm{~h}^{-1}$, o coeficiente de uniformidade também aumentou, mantendo-se entre 94\% a 96\%, sendo estes os melhores valores de uniformidade encontrados nas diferentes vazões, apresentando também diminuição gradativa dos valores após a segunda aplicação de solução no solo.

Observou-se pela vazão de $8 \mathrm{~L} \mathrm{~h}^{-1}$ que os coeficientes de uniformidade se mantiveram intermediários entre as vazões de $2 \mathrm{e}^{\mathrm{L} \mathrm{h} \mathrm{h}} \mathrm{h}^{-1}$ no decorrer das aplicações; porém, ao contrário das vazões de 2 e $4 \mathrm{~L} \mathrm{~h}^{-1}$, a partir da segunda aplicação, houve aumento nos coeficientes de uniformidade até a décima aplicação. Os resultados demonstram uma boa distribuição da solução no solo, uma vez que a disponibilidade dos nutrientes de forma homogênea, na região do sistema radicular da cultura, é estimada para coeficientes de uniformidade superiores a 80\%. Este resultado reflete a homogeneidade no volume de solo molhado próximo ao gotejador. Em cultura intensiva, o teor de água dos solos pode atingir mais de $80 \%$ de uniformidade de distribuição (KELLER \& KARMELI, 1975). OULD MOHAMED EL-HAFEDH et al. (2001) apresentam um coeficiente de uniformidade de $90 \%$ e sugerem que este valor deva ser aceito no sistema de irrigação por gotejamento, principalmente devido à saturação das zonas próximas ao gotejador. Também ZOCOLER (1999) recomenda valores entre 82 e $88 \%$ do CUC, para as culturas cujo sistema radicular explora, basicamente, os primeiros $40 \mathrm{~cm}$ do solo.

O coeficiente de uniformidade da condutividade elétrica obteve média de $84 \%$, sendo que os maiores valores foram encontrados durante as primeiras aplicações de solução no solo (Tabela 3). Verificou-se, que no decorrer das aplicações, houve diminuição gradativa da uniformidade, ficando evidenciado quando comparamos as primeiras com as últimas aplicações nas três vazões $(2 ; 4 \mathrm{e}$ $8 \mathrm{~L} \mathrm{~h}^{-1}$ ) e que os maiores valores de uniformidade foram encontrados na vazão de $4 \mathrm{~L} \mathrm{~h}^{-1}$, com média de $85 \%$.

Analisando-se os dados obtidos no CUC da condutividade elétrica, pode-se afirmar que, para este ensaio, o efeito da aplicação na vazão de maior volume de solução $\left(8 \mathrm{~L} \mathrm{~h}^{-1}\right)$ não teve importância para a melhoria do CUC. Esta constatação reforça a importância de se conhecer a distribuição da solução no solo, por diferentes combinações de vazões de gotejadores. Assim, a solução poderá ser mais uniformemente distribuída no solo, pois aumentando-se o CUC dos valores observados acima, consequentemente, o soluto será distribuído homogeneamente para o sistema radicular da planta, reduzindo a perda de íons pelo processo de lixiviação e contribuindo para o transporte do nutriente para as raízes por fluxo de massa e mecanismos de difusão. 
Na Figura 9, apresenta-se uma avaliação da umidade volumétrica média no volume de controle adotado, facilitando o entendimento de alguns problemas relacionados à uniformidade de distribuição da solução no solo.

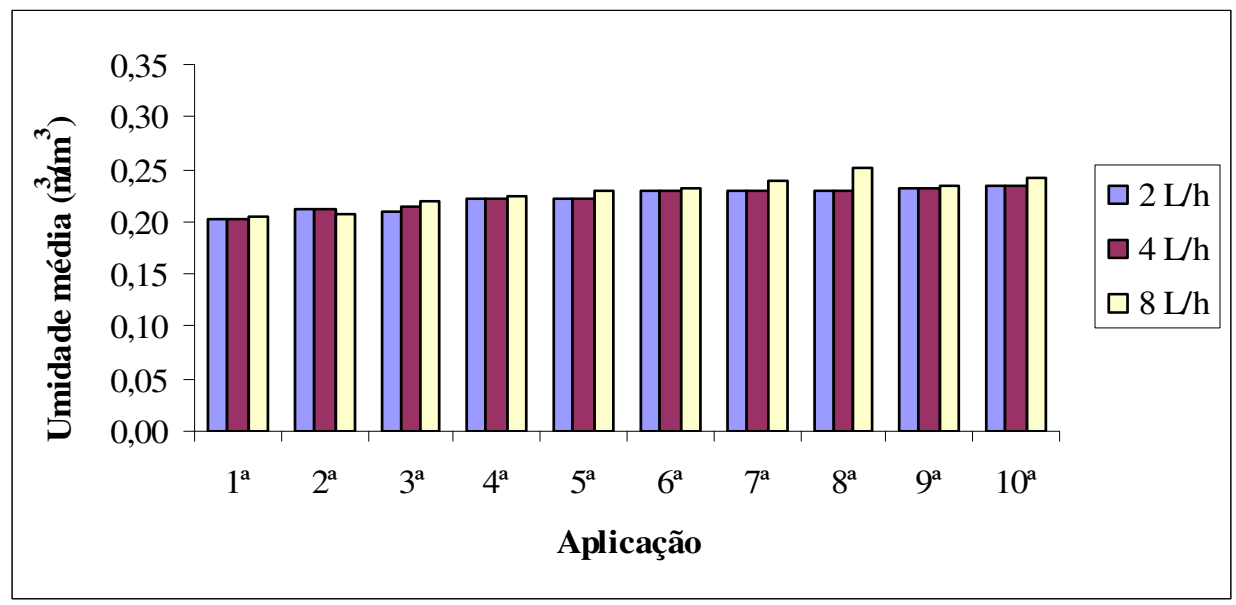

FIGURA 9. Umidade volumétrica média dentro do volume de controle após a aplicação da solução no solo. Average water content inside of the control volume after solution application in the soil.

Pelos dados obtidos, verificou-se que a capacidade de campo do solo (34\%) não foi atingida em nenhum momento no decorrer das aplicações da solução sob as diferentes vazões adotadas $(2 ; 4$ e $8 \mathrm{~L} \mathrm{~h}^{-1}$ ), porém as umidades médias tiveram um pequeno aumento com o volume de solução aplicado no solo, tornando-se visível nas aplicações de $8 \mathrm{~L} \mathrm{~h}^{-1}$, que inicialmente atingiram umidade de 20,5\%, e durante as aplicações atingiram picos de 25\%. Contudo, com os dados observados, pode-se dizer que não houve estabilização da umidade média e, com o acréscimo do volume aplicado, houve um ligeiro aumento da umidade dentro do volume de controle.

\section{CONCLUSÕES}

Com a devida calibração, a TDR e a metodologia aqui apresentadas são muito promissoras no estudo da dinâmica da solução no solo.

As interações entre os diferentes perfis (teor de água versus condutividade elétrica) revelaram um gradiente de distribuição da solução no solo, com maior armazenamento de solução próximo ao gotejador.

Para as condições de solo e de acordo com o volume e a frequência utilizada durante este experimento, recomenda-se a aplicação de pequenas quantidades de solução em intervalos mais frequentes para reduzir a perda por percolação de água e solutos.

\section{AGRADECIMENTOS}

À Fundação de Amparo à Pesquisa do Estado de São Paulo - FAPESP, e ao Conselho Nacional de Desenvolvimento Científico e Tecnológico - CNPq, pelo suporte financeiro.

\section{REFERÊNCIAS}

ALMEIDA, B.P.; CAVALCA, M.; SOUZA, C.F. Calibração da técnica de TDR para estimativa da umidade do solo. In: MOSTRA DE INICIAÇÃO CIENTÍFICA, 12., 2007, Taubaté. Anais... Taubaté: Universidade de Taubaté, 2007. 1 CD-ROM.

BLANCO, F.F.; FOLEGATTI, M.V. Recuperação de um solo salinizado após cultivo em um ambiente protegido. Revista Brasileira de Engenharia Agrícola e Ambiental, Campina Grande, v.5, n.1, p.76-80, 2001. 
BRESLER, E.; HELLER, J.; DINER, N.; BEN ASHER, J.; BRANDT, A.; GLODBERG, D. Infiltration of trickle source: Experimental data and theoretical predictions. Science Society of America Proceedings, Madison, v.35, p.683-689, 1971.

BRESLER, E. Analysis of trickle irrigation with application to design problems. Irrigation Science, New York, v.1, p.3-17, 1978.

CHRISTIANSEN, J.E. The uniformity of application of water by sprinkler systems. Agricultural Engineering, St. Joseph, v.22, p.89-92, 1941.

CLOTHIER, B.E.; SAUER, T.J. Nitrogen transport during drip fertirrigation with area. Soil Science Society America Journal, Madison, v.52, p.345-349, 1988.

COELHO, A.M. Fertirrigação. In: COSTA, E.F.; VIEIRA, R.F.; VIANA, P.A. Quimigação. Sete Lagoas: EMBRAPA/CNMS, 1994. p.201-227.

COELHO, E.F.; OR, D. Flow and uptake patterns affecting soil water sensor placement for drip irrigation management. Transactions of the ASAE, St. Joseph, v.39, p.2.007-2.016, 1996.

COELHO, E.F.; OR, D. Root distribution and water uptake patterns of corn under surface drip irrigation. Plant and Soil, New York, v.206, p.123-136, 1999.

EMBRAPA. EMPRESA BRASILEIRA DE PESQUISA AGROPECUÁRIA. Sistema brasileiro de classificação de solos. Brasília, 1999. 412 p.

EXNER, M.E.; BURBACH, M.E.; WATTS, D.G.; SHEARMAN, R.C.; SPALDING, R.F. Deep nitrate movement in the unsatured zone of simulated urban lawn. Journal Environmental Quality, Madison, v.20, p.658-662, 1991.

GREEN, S.R.; CLOTHIER, B.E. Root water uptake by kiwifruit vines fallowing partial wetting of the root zone. Plant and soil, New York, v.73, p.317-328, 1995.

HAGIN, J.; LOWERGART, A. Fertigation for minimizing environmental pollution by fertilizers. Fertilizer Research, New York, v.43, p.5-7, 1996.

HAMZA, M.; ALYMORE, L.A.G. Soil solute concentration and water uptake by single lupin and radish plant roots. 1. Water extraction and solute accumulation. Plant and soil, New York, v.145, p.187-196, 1992.

KELLER, J.; BLIESNER, R. Sprinkle and trickle irrigation. New York: Chapman and Hall, 1990. $652 \mathrm{p}$.

KELLER, J.; KARMELI, D. Trickle irrigation design. New York: Rain Bird Sprinkler Manufacturing Corporation, 1975. 133 p.

LOPES, L.N.; MARTINS, E.; SANTORO, B.L.; SOUZA, C.F. Caracterização da distribuição da água no solo para irrigação por gotejamento. Irriga, Botucatu, v.14, n.4, p.564-577, 2009.

MAROUELLI, W. A.; SILVA, W. L. C. Irrigação. In: SILVA, J.B.C.; GIORDANO, L.B. Tomate para processamento industrial. Brasília: Embrapa, 2000, p. 60-71.

MMOLAWA, K.; OR, D. Root zone solute dynamics under drip irrigation: Plant and Soil, New York, v.222, p.163-190, 2000.

NADLER, A.; GAMLIEL, A.; PERETZ, I. Practical aspects of salinity effect on TDR-measurement water content: a field study. Soil Science Society America Journal, Madison, v.63, p.1.070-1.076, 1999.

OULD MOHAMED EL-HAFEDH, A.V.; DAGHARI, H.; MAALEJ, M. Analysis of several discharge spacing-duration combinations in drip irrigation system. Agricultural Water Management, Amsterdam, v.52, p.33-52, 2001. 
RICHARDS, L.A. Diagnosis and improvement of saline and alkali soils. Washington: USDA, 1954. 160 p. (Agricultural Handbook, 60).

RIVERA, R.N.C.; DUARTE, S.N.; MIRANDA, J.H.; BOTREL, T.A. Modelagem da dinâmica do potássio no solo sob irrigação por gotejamento: validação do modelo. Engenharia Agrícola, Jaboticabal, v.26, n.2, p.388-394, 2006.

SCHWARTZMAN, M.; ZUR, B. Emitter spacing and geometry of wetted soil volume. Journal of Irrigation and Drainage Engineering, New York, v.112, p.242-253, 1986.

SOUSA, V.F.; COELHO, E.F. Manejo da fertirrigação em fruteiras. In: FOLEGATTI, M.V.; CASARINI, E.; BLANCO, F.F.; BRASIL, R.P.C.; RESENDE, R.S. Fertirrigação: citrus, flores, hortaliças. Guaíba: Agropecuária, 2001. p.289-317.

SOUZA, C.F.; MATSURA, E.E. Distribuição da água no solo para o dimensionamento da irrigação por gotejamento. Revista Brasileira de Engenharia Agrícola e Ambiental, Campina Grande, v.8, n.1, p.7-15, 2004.

SOUZA, C.F.; MATSURA, E.E.; FOLEGATTI, M.V.; COELHO, E.F.; OR, D. Sondas de TDR para a estimativa da umidade e da condutividade elétrica do solo. Irriga, Botucatu, v.11, n.1, p.1225, 2006a.

SOUZA, C.F.; FOLEGATTI, M.V.; MATSURA, E.E.; OR, D. Calibração da reflectometria no domínio do tempo (TDR) para a estimativa da concentração da solução no solo. Engenharia Agrícola, Jaboticabal, v.26, n.1, p.282-291, 2006 b.

SOUZA, C.F.; SILVA, E.F.F.; FOLEGATTI, M.V.; OR, D. Irrigação por gotejamento: disco saturado e área superficial molhada versus distribuição e armazenamento da água no solo. Revista Brasileira de Ciências Agrárias, Recife, v.1, n.1, p.65-71, 2006c.

SOUZA, C.F.; MARTINS, R.B.T.; FOLEGATTI, M.V.; DAROZ, T.H.C.; SILVA, E.F.F. Uso da reflectometria no domínio do tempo (TDR) para avaliar a distribuição do nitrato no volume molhado do solo sob fertirrigação. Magistra, Cruz das Almas, v.19, p.112-122, 2007.

SOUZA, C.F.; FOLEGATTI, M.V.; OR, D. Distribution and storage characterization of soil solution for drip irrigation. Irrigation Science, New York, v.27, n.4, p.277-288, 2009.

SOUZA, C.F.; FOLEGATTI, M.V. Spatial and temporal characterization of water and solute distribution patterns. Scientia Agricola, Piracicaba, v.67, n.1, p.9-15, 2010.

SPALDING, R.F.; EXNER, M.E.; LINDAU, C.W.; EATON, D.W. Investigation of sources of groundwater nitrate contamination in the Burbank Wallula area of Washington, USA. Journal of Hydrology, Amsterdam, v.58, p.307-324, 1982.

VALOCCHI, A.J. Describing the transport of ion-exchanging contaminants using an effective Kd approach. Water Resources Research, Washington, v.20, p.499-503, 1984.

WU, I.P.; GITLIN, H.M. Drip irrigation application efficiency and schedules. Transactions of the ASAE, St. Joseph, v.26, p.92-99, 1983.

ZOCOLER, J.L. Avaliação do desempenho de sistemas de irrigação In: CURSO CAPACITAÇÃO EM AGRICULTURA IRRIGADA, 1., 1999, Ilha Solteira, Anais... Ilha Solteira: UNESP/FEIS, 1999. $55 \mathrm{p}$. 